\title{
Management of suspected common bile duct stones on cholangiogram during same-stay cholecystectomy for acute gallstone-related disease
}

Sandra de Sousa ${ }^{1 *}$ (D), Olivier Tobler ${ }^{1}$, Pouya Iranmanesh ${ }^{1}$, Jean-Louis Frossard ${ }^{2,3}$, Philippe Morel ${ }^{1,3}$ and Christian Toso $0^{1,3}$

\begin{abstract}
Background: Recent data have suggested that upfront cholecystectomy should be performed even in the presence of moderately abnormal liver function tests (LFTs). As a consequence, more common bile duct (CBD) stones are discovered on intra-operative cholangiogram. We assessed the presentation and management of such patients to refine their management plan.

Methods: Adult patients (>16 years) with an acute gallstone-related disease who had undergone same-stay cholecystectomy from January 2013 to January 2015 were retrospectively assessed. We excluded patients with pre-operative endoscopic CBD exploration.

Results: Among the 612 patients with same-stay cholecystectomy, 399 patients were included in the study, and 213 were excluded because of a pre-operative CBD exploration. Fifty patients (12.5\%) presented an image of CBD stone on the intra-operative cholangiogram. Such patients were younger ( $47 \mathrm{vs.} 55$ years, $P=.01$ ) and less likely to present with fever ( 1 vs. $11.7 \%, P=.04$ ) or signs of cholecystitis on ultrasound (66 vs. 83.7\%, $P=.003$ ). Admission LFTs were higher in patients with an image of a stone. Among the 50 patients with an image on cholangiogram, a stone was confirmed in 26 (52\%). Most patients ( $n=32$ ) underwent post-operative assessment with endoscopic ultrasound (EUS). LFTs did not predict the presence of a confirmed stone. However, the absence of contrast passage into the duodenum was negatively associated with a confirmed stone $(P=.08)$, and a filling defect was positively associated with one $(P=.11)$. Most confirmed stones were successfully extracted by endoscopic retrograde cholangiopancreatogram (ERCP) (25/26, 96\%), except in one patient who needed a per-cutaneous approach because of duodenal diverticuli.

Conclusions: Same-stay cholecystectomy can (and should) be performed even in the presence of moderately abnormal liver function tests. The cholangiogram suspicion of a CBD stone is confirmed in only half of the patients (more often in the presence of a filling defect, and less often with the absence of contrast passage). All stones can be safely treated after surgery (most by ERCP).
\end{abstract}

Keywords: Suspected common bile duct stone, Same-stay cholecystectomy for acute gallstone-related disease, Filling defect on intra-operative cholangiogram, Trans-cystic drain

\footnotetext{
* Correspondence: sandra.desousa@hcuge.ch

'Division of Abdominal Surgery, Geneva University Hospitals, Faculty of

Medicine, Rue Gabrielle-Perret-Gentil 4, 1205, Geneva, Switzerland

Full list of author information is available at the end of the article
} 


\section{Background}

Gallstones are common and affect $10-15 \%$ of the adult population. Some $4 \%$ of these patients become symptomatic each year, with biliary colics, cholecystitis or cholangitis [1, 2]. In addition, $10-15 \%$ of the patients with symptoms also present a common bile duct (CBD) stone [3].

The likelihood of an associated CBD stone and its management have been established by the American Society for Gastrointestinal Endoscopy (ASGE) and Society of American Gastrointestinal and Endoscopic Surgeons (SAGES) guidelines [4]. Globally, patients with normal liver function tests (LFTs) are at low risk $(<5 \%)$ for a CBD stone and should undergo cholecystectomy first. Those with elevated liver function tests (LFTs) are at increased risk, especially those with total bilirubin $>70 \mu \mathrm{mol} / \mathrm{l}$, which carries a risk for a CBD stone $>50 \%$. They should undergo a preliminary exploration of the CBD prior to cholecystectomy. We recently demonstrated that intermediate-risk patients with moderately elevated LFTs (including bilirubin $<70 \mu \mathrm{mol} / \mathrm{l}$ ) are best treated by upfront same-stay cholecystectomy with intra-operative cholangiogram [5]. This strategy is associated with a decreased length of stay and the need for fewer CBD investigations compared with a primary CBD exploration followed by cholecystectomy. The net effect is that more patients are discovered with an intra-operative CBD stone during same-stay cholecystectomy, and a routine intraoperative cholangiogram is needed $[4,5]$.

The factors predicting the presence of a CBD stone could still be improved. Such factors could be applied prior to or during surgery. However, a perfect split between patients with and without stone will likely never occur due to the heterogeneity of the signs linked to a CBD stone and because some patients present interval migrations (prior to or during cholecystectomy). Finally, many patients show a spontaneous migration to the duodenum [6]; therefore, a cholangiogram image of a stone does not necessarily translate into a stone on the post-operative assessment.

The aims of our study were therefore to (a) explore factors predicting the presence of a CBD stone image during upfront surgery, to (b) define the predictors of a stone on the post-operative assessment in patients with an image of a CBD stone on cholangiogram, and to (c) explore the efficiency of a post-operative EUS/ERCP management in case of intra-operative $\mathrm{CBD}$ stone discovery.

\section{Methods}

\section{Study design}

The study included a retrospective assessment of adult patients (>16 years) with acute gallstone-related disease who had undergone same-stay cholecystectomy from 01.01.2013 to 01.01.2015. Those with a suspected intraoperative CBD stone on cholangiogram were specifically assessed.

Inclusion criteria were: (a) adult patients ( $>16$ years) admitted through the emergency room at the Geneva University Hospitals with a history of acute right upper quadrant pain, (b) radiologically proven gallbladder stone, (c) treatment by cholecystectomy during the same admission, and (d) the absence of CBD investigation prior to cholecystectomy.

Overall, patients presented with (a) prolonged biliary colic, with right upper quadrant pain $>6 \mathrm{~h}$, (b) acute cholecystitis with pain, blood signs of inflammation/infection, and a compatible ultrasound assessment, or (c) cholangitis as previously defined [7]. Data were prospectively collected during the hospital stay and analysed at the end of the inclusion period.

\section{Management}

Patients could be categorized into three groups according to their risk of presenting a CBD stone following the ASGE/SAGE guidelines [4]. Low-risk patients demonstrated normal LFTs. High-risk patients included those with serum bilirubin $\geq 70 \mu \mathrm{mol} / \mathrm{l}$, a visible stone on pre-op imaging (ultrasound (US) or computed tomography (CT)), an ascending cholangitis, and those with bilirubin $30-70 \mu \mathrm{mol} / \mathrm{l}$ and CBD diameter $>6 \mathrm{~mm}$. Patients at intermediate risk of a CBD stone included those with abnormal LFTs not fulfilling the aforementioned criteria for high risk of a CBD stone. Based on a recent randomized clinical trial, patients at low and intermediate risk of a CBD stone were managed by cholecystectomy first [5] and represented the target population of patients included in the present study. High-risk patients underwent primary CBD endoscopic exploration followed by cholecystectomy and were not included in the present analysis to improve the population homogeneity.

All patients underwent same-stay laparoscopic cholecystectomy with intra-operative cholangiogram (IOC). Of note, the local policy to systematically performed an IOC is based on safety and didactic reasons, and is aiming at better identifying CBD stones. It is not fully supported by the current literature [8-10]. The cholangiogram looked for a filling defect compatible with a stone, the presence/absence of contrast passage into the duodenum, and a potential iatrogenic bile duct lesion. Patients with a suspected CBD stone on the IOC underwent a post-operative CBD exploration, most often based on endoscopic ultrasound (EUS) followed by endoscopic retrograde cholangiopancreatogram (ERCP) in the case of a confirmed stone. According to the clinical situation, and based 
on the surgeon's decision, some patients could be managed with a trans-cystic drain (Escat $\mathrm{CH} 6$ drain, Coloplast, Coloplast Group, Denmark).

\section{Variables of interest}

The main outcome of interest was the presence of an image of a CBD stone detected on IOC (filling-defect and/or the absence of contrast passage into the duodenum). We further assessed the patients with a confirmed stone on post-operative EUS.

Studied variables included demographic data (age, gender, body mass index (BMI)), admission data (fever, right upper quadrant pain, signs of cholecystitis on US, admission LFTs), and outcome data (length of hospital stay, conversion rate to a laparotomy, complications according to the Dindo/Clavien classification [11]). In addition, we recorded post-operative LFTs in the patients with an image of a CBD stone on the IOC.

\section{Statistical analysis and ethics}

Demographic and admission data were compared between patients with or without the image of a CBD stone on IOC to look for predictors of intra-operative stone. IOC characteristics and post-operative LFTs were compared between patients with or without a confirmed stone on post-operative EUS to identify predictors of a confirmed CBD stone on post-operative EUS. The groups were compared with Student's $t$-test and Chi-squared tests. The standard alpha level of .05 indicated statistical significance. Analyses were conducted using SPSS 18.0 (SPSS, Chicago, IL). Ethical approval was obtained from the Institutional Ethical Review Board under the number GE 15-087.

\section{Results}

\section{Predictors of a CBD stone on IOC}

During the study period, 612 adult patients were admitted for an acute gallstone-related disease and underwent a cholecystectomy. Among them, 399 patients were included in the study, and 213 were excluded because they underwent a pre-operative CBD assessment. Most of the patients were female $(56.1 \%)$, with a mean age of $56 \pm$ 19 years and a mean BMI of $28 \pm 6 \mathrm{~kg} / \mathrm{m}^{2}$ (Table 1). Only two other patients were admitted during the study period, and were not included because they underwent a delayed cholecystectomy in subsequent hospital stay.

Among the 399 studied patients with upfront cholecystectomy, 50 (12.5\%) presented an image of a CBD stone on IOC (Table 1). Such patients were younger (47 vs. 55 years, $P=.01)$ than those without an image of a CBD stone on IOC. In addition, they were less likely to present fever on admission (2 vs. $11.7 \%, P=.04)$ or an associated

Table 1 Demographics and presentation comparing patients with or without a common bile duct stone image on cholangiogram

\begin{tabular}{|c|c|c|c|c|c|}
\hline & & $\begin{array}{c}\text { Total } \\
(N=399)\end{array}$ & $\begin{array}{l}\text { CBD stone } \\
(N=50)\end{array}$ & $\begin{array}{c}\text { No CBD stone } \\
(N=349)\end{array}$ & $P$ value \\
\hline \multirow[t]{2}{*}{ Gender } & Male, No. (\%) & $175(43.9 \%)$ & $16(32 \%)$ & $159(45.6 \%)$ & .07 \\
\hline & Female, No. (\%) & $224(56.1 \%)$ & $34(68 \%)$ & $190(54.4 \%)$ & \\
\hline Age (mean $\pm S D)$, years & & $56 \pm 19$ & $47 \pm 20$ & $55 \pm 18$ & .01 \\
\hline $\mathrm{BMI}($ mean $\pm \mathrm{SD}), \mathrm{kg} / \mathrm{m}^{2}$ & & $28 \pm 6$ & $29 \pm 6$ & $28 \pm 5$ & .58 \\
\hline \multirow[t]{3}{*}{ Clinical presentation } & Fever, No. (\%) & $42(10.5 \%)$ & $1(2 \%)$ & $41(11.7 \%)$ & .04 \\
\hline & RUQ pain on admission, No. (\%) & 355 (89\%) & 42 (84\%) & $313(89.7 \%)$ & .23 \\
\hline & Associated cholecystitis, No. (\%) & $325(81.5 \%)$ & $33(66 \%)$ & $292(83.7 \%)$ & .003 \\
\hline \multirow[t]{6}{*}{ Admission LFTs (mean \pm SD) } & ASAT, IU/L & & $167 \pm 184$ & $67 \pm 146$ & .001 \\
\hline & ALAT, IU/L & & $166 \pm 197$ & $68 \pm 121$ & .001 \\
\hline & $P A, I U / L$ & & $123 \pm 97$ & $81 \pm 48$ & .005 \\
\hline & GGT, IU/L & & $245 \pm 276$ & $94 \pm 139$ & .001 \\
\hline & Total Bilirubin, $\mu \mathrm{mol} / \mathrm{L}$ & & $26 \pm 17$ & $20 \pm 12$ & .01 \\
\hline & Conjugated Bilirubin, $\mu \mathrm{mol} / \mathrm{L}$ & & $18 \pm 10$ & $9 \pm 7$ & .002 \\
\hline \multirow[t]{6}{*}{ Abnormal admission LFTs } & ASAT (11-42 IU/L), No. (\%) & $162(40.6 \%)$ & $36(72 \%)$ & $126(36.1 \%)$ & $<.001$ \\
\hline & ALAT (9-42 IU/L), No. (\%) & $163(40.9 \%)$ & $34(68 \%)$ & $129(37 \%)$ & $<.001$ \\
\hline & PA (30-125 IU/L), No. (\%) & 75 (18.8\%) & $14(28 \%)$ & $61(17.5 \%)$ & .07 \\
\hline & GGT (9-35 IU/L), No. (\%) & $261(65.4 \%)$ & $43(86 \%)$ & $218(62.5 \%)$ & .001 \\
\hline & Total Bilirubin (7-25 umol/L), No. (\%) & 97 (24.3\%) & $20(40 \%)$ & $77(22.1 \%)$ & .006 \\
\hline & Conjugated Bilirubin (2-9 $\mu \mathrm{mol} / \mathrm{L})$, No. (\%) & 319 (79.9\%) & $45(90 \%)$ & $274(78.5 \%)$ & .06 \\
\hline
\end{tabular}


cholecystitis on ultrasound ( 66 vs. $83.7 \%, P=.003$ ). Finally, they demonstrated significantly higher admission LFTs (Table 1). We also assessed similar criteria only looking at patients with intermediate risk of CBD stone (demonstrating similar results as when using the entire cohort) (Additional file 1: Table S1).

In the $\mathrm{CBD}$ stone group $(N=50)$, all patients were assessed by IOC. In the No CBD stone group $(N=349)$, the IOC success rate was $81.4 \%(284 / 349)$. In the 65 patients without IOC, the absence of CBD stone was confirmed by MRCP, EUS, ERCP and by following the LFTs until their normalization, and checking the absence of subsequent management for a CBD stone.

Of note the present failure rate is similar to previous ones $[9,10]$.

\section{Management of patients with a suspected CBD stone on IOC}

A total of 50 patients demonstrated an image of a suspected stone on IOC, including 15 (15/50, 30\%) with difficult or no contrast passage into the duodenum and $46(46 / 50,92 \%)$ with a filling defect compatible with a CBD stone. Among them, 45 patients underwent a post-operative CBD assessment $1.8 \pm 1.2$ days after surgery (Fig. 1). Among them, 32 underwent post-operative EUS, which confirmed the presence of a CBD stone in 17 patients (53.1\%). All but one obtained a successful CBD clearance by ERCP. The only failure was linked to the presence of a duodenal diverticuli, and the stone was extracted by interventional radiology. Seven patients underwent post-operative
ERCP without previous EUS. Six of them had a confirmed CBD stone, all successfully extracted. In addition, four patients underwent post-operative magnetic resonance cholangiopancreatography (MRCP), all negative. Two patients were followed with normalized LFT levels, as they refused any further investigation.

One patient underwent intra-operative ERCP with successful stone extraction. Two underwent laparoscopic stone extraction utilizing a Dormia basket. Two patients had a cholangiography through a transcystic drain left during surgery before EUS/ERCP. As this examination was negative, no further endoscopic assessment was performed, and the patients had drain removal a few weeks later.

Linked to the need for added investigation/intervention, patients with an image of a CBD stone on cholangiogram showed a longer length of stay, but the rates of major (stage 3 and 4) complications were not significantly different $(6 / 50,12 \%$ vs. $22 / 349,6 \%, P=.14$, (Table 2)).

In the CBD stone group, one patient $(1 / 50,2 \%)$ has been converted from laparoscopy to laparotomy because of adhesions and a stomach sero-muscular lesion. In addition, another patient underwent a laparotomy first due to a patent foramen ovale. In the No CBD stone group, 7 patients had a conversion $(7 / 349,2 \%)$, due to adhesions, severe pediculitis, haemorrhage, small bowel perforation, lack of identification of the cystic duct and necrotized gallbladder with peritonitis. In addition, two other patients

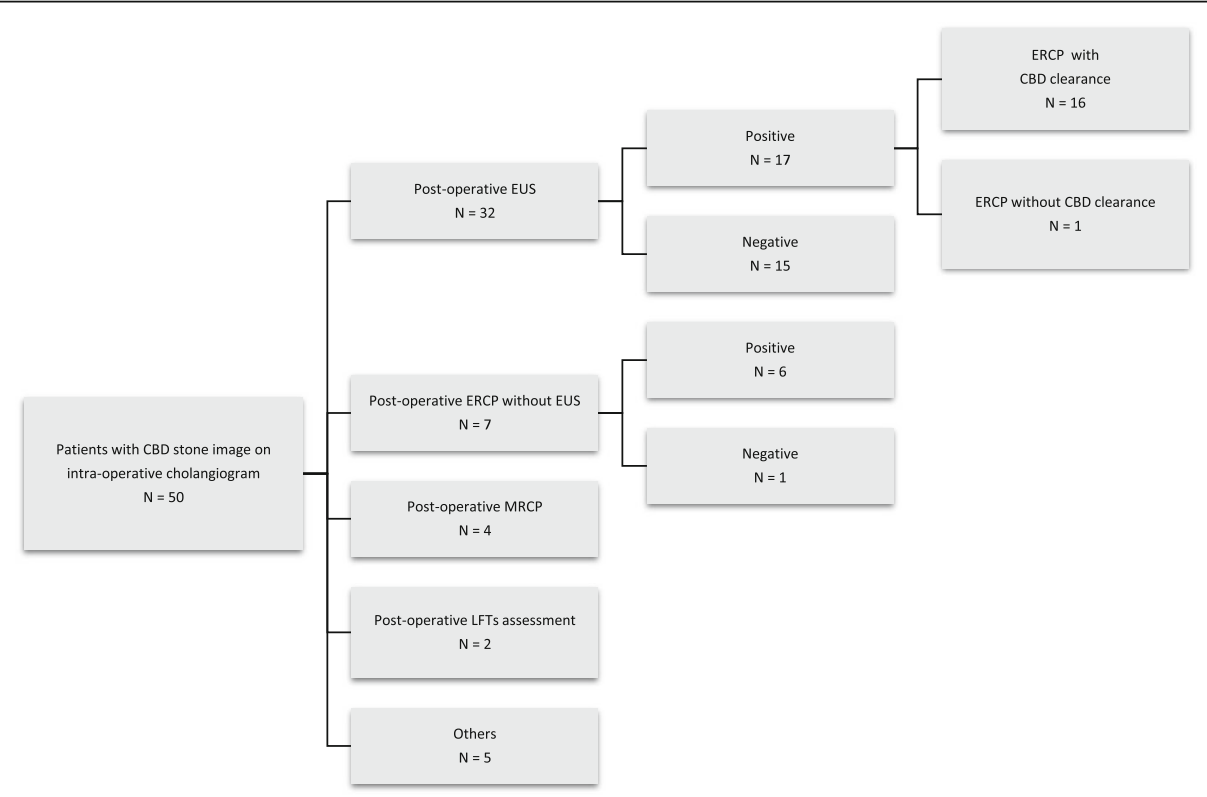

Fig. 1 Management of patients with a CBD stone image on intra-operative cholangiogram. CBD Common Bile Duct, LFTs Liver Function Tests, EUS Endoscopic Ultrasound, ERCP Endoscopic Retrograde Cholangiopancreatography, MRCP Magnetic Resonance Cholangiopancreatography 
Table 2 Outcomes

\begin{tabular}{|c|c|c|c|c|c|}
\hline & Total & CBD stone & $\begin{array}{l}\text { No CBD } \\
\text { stone }\end{array}$ & $P$ value \\
\hline & & $(N=399)$ & $(N=50)$ & $(N=349)$ & \\
\hline \multicolumn{2}{|l|}{$\begin{array}{l}\text { Conversion from } \\
\text { LS to } L T \text {, No. (\%) }\end{array}$} & $8(2 \%)$ & $1(2 \%)$ & $7(2 \%)$ & .998 \\
\hline \multicolumn{2}{|l|}{$\begin{array}{l}\text { Laparotomy first, } \\
\text { No. (\%) }\end{array}$} & $3(0.8 \%)$ & $1(2 \%)$ & $2(0.6 \%)$ & .275 \\
\hline \multicolumn{2}{|l|}{$\begin{array}{l}\text { LOS (mean } \pm S D \text { ), } \\
\text { days }\end{array}$} & $6.9 \pm 4$ & $8.8 \pm 4.7$ & $6.6 \pm 3.8$ & .003 \\
\hline \multirow{2}{*}{$\begin{array}{l}\text { Complications } \\
\text { (Dindo-Clavien } \\
\text { classification) }\end{array}$} & $\begin{array}{l}\text { Grade } \\
\text { III, No }\end{array}$ & 21 & 4 & 17 & .35 \\
\hline & $\begin{array}{l}\text { Grade } \\
\text { IV, No }\end{array}$ & 7 & 2 & 5 & .2 \\
\hline
\end{tabular}

underwent a laparotomy first due to severe heart failure and septic shock.

\section{Predictors of a CBD stone on post-operative CBD assessment}

To identify predictors of confirmed CBD stones on post-operative EUS (only this group was used for a better homogeneity), the 15 patients with no sign of a remaining stone were compared with the 17 with a confirmed stone. The time between surgery and EUS was similar between the two groups (Table 3). LFTs assessed prior to EUS did not predict the presence of a stone on EUS (Table 3). An image of a filling defect on IOC compatible with a CBD stone tended to predict the presence of a confirmed stone $(P=.11)$. Conversely, the absence of contrast passage into the duodenum tended to be associated with an absence of a stone on EUS $(P=.08)$.

\section{Impact of a trans-cystic drain}

Of the patients described earlier, five $(5 / 50,10 \%)$ were managed with a transcystic drain. Among them, 3 (3/5, $60 \%)$ had no contrast passage into the duodenum. The delay between surgery and post-operative CBD investigation was significantly shorter for the group of patients with a transcystic drain than for those without a drain $(1 \pm 0.4$ vs. $2 \pm 1.3$ days, $P=.003)$. There was no significant difference in the length of stay (LOS) (11 \pm 8 vs. 9 \pm 4 days, $P=.56$ ). Complication rates were similar, but one patient developed a stage 4 Dindo/Clavien complication due the displacement of the trans-cystic drain (Table 4).

\section{Discussion}

The risk of a CBD stone is classically defined by a combination of clinical, biological and radiological parameters [4]. The present study assessed patients without previous $\mathrm{CBD}$ exploration and confirmed the value of LFTs, and clinical variables such as fever, as well as signs of cholecystitis on US [12]. In addition, women were more likely to present a stone.

Despite these known risk factors, our local policy is to perform an IOC in all patients undergoing cholecystectomy because models predicting the presence of a stone are not accurate enough [10-12]. Alternatively, IOC appears as efficient as ERCP in predicting the presence of a stone $[13,14]$. Additionally, it bears a didactic value, training younger surgeons at approaching the CBD for a potential exploration. Finally, IOC also helps to detect an

Table 3 Comparison of patients with positive versus negative post-operative endoscopic ultrasound

\begin{tabular}{|c|c|c|c|c|}
\hline & & $\begin{array}{l}\text { Positive EUS } \\
\qquad(N=17)\end{array}$ & $\begin{array}{l}\text { Negative EUS } \\
\qquad(N=15)\end{array}$ & $P$ value \\
\hline \multirow[t]{6}{*}{ LFTs before EUS } & ASAT, IU/L & $119 \pm 120$ & $100 \pm 87$ & 62 \\
\hline & ALAT, IU/L & $151 \pm 194$ & $167 \pm 117$ & .79 \\
\hline & $\mathrm{PA}, \mathrm{IU} / \mathrm{L}$ & $128 \pm 89$ & $86 \pm 43$ & .18 \\
\hline & GGT, IU/L & $290 \pm 265$ & $260 \pm 233$ & .76 \\
\hline & Total Bilirubin, $\mu \mathrm{mol} / \mathrm{L}$ & $24 \pm 15$ & $33 \pm 28$ & .28 \\
\hline & Conjugated Bilirubin, $\mu \mathrm{mol} / \mathrm{L}$ & $21 \pm 12$ & $31 \pm 21$ & .34 \\
\hline Pancreatic tests before EUS & Lipase, IU/L & $26 \pm 9$ & $108 \pm 192$ & .3 \\
\hline \multirow[t]{4}{*}{ Intra-operative cholangiogram } & Filling defect present, No. & 16 & 11 & .11 \\
\hline & absent, No. & 1 & 4 & \\
\hline & Contrast in duodenum present, No. & 14 & 8 & .08 \\
\hline & absent, No. & 3 & 7 & \\
\hline $\begin{array}{l}\text { Delay between surgery and } \\
\text { post-operative EUS, days }\end{array}$ & & $1.8 \pm 0.8$ & $1.9 \pm 1.4$ & .81 \\
\hline
\end{tabular}

LFTs Liver Function Tests, EUS Endoscopic Ultrasound

ASAT Aspartate Aminotransferase, ALAT Alanine Aminotransferase, PA Alkaline Phosphatase, GGT Gamma-glutamyl Transferase 
Table 4 Usefulness and safety of transcystic drainage in patients with an intra-operative suspicion of common bile duct stone

\begin{tabular}{|c|c|c|c|c|}
\hline & & $\begin{array}{c}\text { Patients with transcystic } \\
\text { drainage }(N=5)\end{array}$ & $\begin{array}{l}\text { Patients without transcystic } \\
\text { drainage }(N=45)\end{array}$ & $P$ value \\
\hline \multirow{2}{*}{$\begin{array}{l}\text { Duodenal passage of contrast } \\
\text { product during IOC }\end{array}$} & Difficult duodenal passage, No. & $2(40 \%)$ & $4(9 \%)$ & .04 \\
\hline & No duodenal passage, No. & $3(60 \%)$ & $4(9 \%)$ & .002 \\
\hline $\begin{array}{l}\text { Delay between surgery and } \\
\text { post-operative CBD assessment, days }\end{array}$ & & $1 \pm 0.4$ & $2 \pm 1.3$ & .003 \\
\hline Length of stay (mean $\pm S D$ ), days & & $11 \pm 8$ & $9 \pm 4$ & .56 \\
\hline $\begin{array}{l}\text { Length of transcystic drainage } \\
\text { (mean } \pm S D) \text {, days }\end{array}$ & & $39 \pm 22$ & 0 & \\
\hline \multirow{4}{*}{$\begin{array}{l}\text { Complications } \\
\text { (Dindo-Clavien classification) }\end{array}$} & Grade I, No. & 0 & 7 & .34 \\
\hline & Grade II, No. & 0 & 3 & .55 \\
\hline & Grade III, No. & 0 & 4 & .49 \\
\hline & Grade IV, No. & 1 & 1 & .05 \\
\hline
\end{tabular}

IOC Intra-operative Cholangiogram, CBD Common Bile Duct, SD Standard Deviation

iatrogenic bile duct lesion [15]. We acknowledge, however, that patients with normal LFTs undergoing elective cholecystectomy do not necessarily need an IOC. Conversely, we strongly recommend following the IOC path in patients undergoing cholecystectomy for acute gallstonerelated diseases, especially in the case of abnormal LFTs.

Overall, an intra-operative stone was suspected in $12.5 \%$ (50/399) of the studied patients, based on IOC abnormalities. The preliminary injection of a limited quantity of contrast agent helps to detect a filling defect, while a stone can be less visible after the injection of a large volume of contrast agent. Of note, manoeuvres such as changing the table position and/or injecting saline help in the differential diagnosis with an air bubble. The second type of abnormality is the lack or a difficult contrast passage into the duodenum, which may be due to a trapped CBD stone, an Oddi's sphincter spasm, or a lesion of the sphincter (neoplasia/ inflammation).

Only half of the suspected stones could be confirmed post-operatively. Based on the current data, it remains difficult to predict which patients will finally present a confirmed stone. Post-operative LFTs have no predictive power. LFTs may remain increased because of the previous injection of contrast during IOC or because a liver lesion occurred during the removal of the gallbladder from its bed. Only the presence of a filling defect tends to be predictive of a remaining CBD stone, whereas the absence of contrast passage into the duodenum is not. Most contrast passage alterations are likely linked to spasms. The net results of these observations are that a post-operative CBD assessment is required in all patients with an IOC abnormality and that LFTs do not necessarily need to be repeated after surgery due to their low predictive value.

We favour the use of post-operative EUS (+/-ERCP) in patients with an image of a stone during same-stay cholecystectomy. In fact, EUS accuracy is very high (near 97\%) as are the sensitivity $(71-100 \%)$, specificity $(67-100 \%)$ and the positive or negative predictive values [16-19].

Such a strategy allowed the extraction of all stones by ERCP (with the exception of one patient treated by interventional radiology). As an alternative, laparoscopic CBD exploration could also be used. However, it can require the use of laparoscopic choledochotomy, with a risk of bile leak up to $15 \%$, especially in patients with non-dilated $\mathrm{CBD}$, and in the presence of inflammation [20]. In addition, the ERCP stone clearance rate appears higher than that after laparoscopic bile duct exploration [21, 22].

Another option would have been to perform ERCP during surgery (with or without rendezvous) [23]. Here again, we have not selected this strategy primarily because half of the patients do not show a confirmed stone on postoperative tests (and would have undergone unnecessary ERCP). Secondarily, emergency intra-operative ERCP is difficult to organize because of endoscopist availability and the positioning of the patient being non-standard for ERCP. The present study is limited by its retrospective nature and its potential for type 2 errors. However, it provides a real-life assessment of the proposed management strategy of patients at risk of CBD stones.

The present study is limited by its retrospective nature and its potential for type 2 errors. However, it provides a real-life assessment of the proposed management strategy of patients at risk of CBD stones.

\section{Conclusion}

As a whole, the present study confirms that same-stay cholecystectomy can (and should) be performed even in the presence of moderately abnormal liver function tests. The cholangiogram suspicion of a CBD stone can be confirmed in only half of the patients (more often in the presence of a filling defect, and less often with the absence of contrast passage). All stones can be safely treated after surgery (most by ERCP). 


\section{Additional file}

Additional file 1: Table S1. Demographics and presentation comparing intermediate risk patients with or without a common bile duct stone image on cholangiogram. Assessment of demographic and clinical criteria considering only the patients at intermediate risk of CBD stone. The results were similar to those using the entire cohort. (PDF $15 \mathrm{~kb}$ )

\begin{abstract}
Abbreviations
ALAT: Alanine aminotransferase; ASAT: Aspartate aminotransferase; ASGE: American Society for Gastrointestinal Endoscopy; BMI: Body mass index; CBD: Common bile duct; CT: Computed tomography; ERCP: Endoscopic retrograde cholangiopancreatogram; EUS: Endoscopic ultrasound; GGT: Gamma-glutamyl transferase; IOC: Intra-operative cholangiogram; LFTs: Liver function tests; LOS: Length of stay; LS: Laparoscopy; LT: Laparotomy; MRCP: Magnetic resonance cholangiopancreatography; PA: Alkaline phosphatase; RUQ: Right upper quadrant; SAGES: Society of American Gastrointestinal and Endoscopic Surgeons; SD: Standard deviation; US: Ultrasound
\end{abstract}

\section{Acknowledgements}

CT was supported by the Swiss National Science Foundation (PPO0P3_139021).

\section{Funding}

Christian Toso, MD, PhD, received salary support from the Swiss National Science Foundation (PPOOP3_139021). This grant was not given specifically for the present study and was not used to conduct it.

\section{Availability of data and materials}

The datasets used and/or analysed during the current study are available from the corresponding author on reasonable request.

\section{Authors' contributions}

All authors read and approved the final manuscript. The specific contributions of each author are as follows: SdS: study design, study protocol creation, literature search, data collection, data analysis, data interpretation, figure and table creation, manuscript writing. OT: study design, data collection, manuscript revision. IP: study design, data collection, manuscript revision. J-LF: study design, manuscript revision. PM: study design, manuscript revision. CT: study design, study protocol creation, data analysis, data interpretation, figure and table creation, manuscript correction.

\section{Competing interests}

The authors declare that they have no competing interests.

\section{Consent for publication}

Not applicable.

\section{Ethics approval and consent to participate}

Ethical approval was obtained from the Institutional Ethical Review Board under the number GE 15-087. Of note, it has waved the request for a written informed consent from each patient due to the retrospective nature of study, the large number of patients, and the relatively high gain in knowledge compared to the large amount of work required to specifically consent each patient.

\section{Publisher's Note}

Springer Nature remains neutral with regard to jurisdictional claims in published maps and institutional affiliations.

\section{Author details}

${ }^{1}$ Division of Abdominal Surgery, Geneva University Hospitals, Faculty of Medicine, Rue Gabrielle-Perret-Gentil 4, 1205, Geneva, Switzerland. ²Division of Gastro-intestinal Disease and Hepatology, Geneva University Hospitals, Faculty of Medicine, Geneva, Switzerland. ${ }^{3}$ Hepato-pancreatico-biliary Center, Geneva University Hospitals, Faculty of Medicine, Geneva, Switzerland.
Received: 6 December 2016 Accepted: 31 March 2017

Published online: 17 April 2017

\section{References}

1. Stinton LM, Shaffer EA. Epidemiology of Gallbladder Disease: Cholelithiasis and Cancer. Gut Liver. 2012;6(2):172-87.

2. Everhart JE, Khare M, Hill M, Maurer KR. Prevalence and Ethnic Differences in Gallbladder Disease in the United States. 1999. p. 632-9.

3. Horwood J, Akbar F, Katherine D, Morgan R. Prospective evaluation of a selective approach to cholangiography for suspected common bile duct stones. Ann R Coll Surg Engl. 2010;92(3):206-10. doi:10.1308/ $003588410 \times 12628812458293$

4. Maple JT, Ben-Menachem T, Anderson MA, et al. The role of endoscopy in the evaluation of suspected choledocholithiasis. Gastrointest Endosc. 2010; 71(1):1-9. doi:10.1016/j.gie.2009.09.041.

5. Iranmanesh P, Frossard J-L, Mugnier-Konrad B, et al. Initial cholecystectomy vs sequential common duct endoscopic assessment and subsequent cholecystectomy for suspected gallstone migration: a randomized clinical trial. JAMA. 2014;312(2):137-44. doi:10.1001/jama.2014.7587.

6. Frossard JL, Hadengue A, Amouyal G, et al. Choledocholithiasis: a prospective study of spontaneous common bile duct stone migration. Gastrointest Endosc. 2000;51(2):175-9. doi:10.1016/S0016-5107(00)70414-7.

7. Takada T, Strasberg SM, Solomkin JS, Pitt HA, Gomi H, Yoshida M. TG13: Updated Tokyo Guidelines for the management of acute cholangitis and cholecystitis. 2013. p. 1-7. doi:10.1007/s00534-012-0566-y.

8. Agresta F, Campanile FC, Vettoretto N, et al. Laparoscopic cholecystectomy consensus conference-based guidelines. Langenbecks Arch Surg. 2015;429453. doi:10.1007/s00423-015-1300-4.

9. Buddingh KT, Bosma BM, Ploeg RJ, et al. Kumar versus Olsen cannulation technique for intraoperative cholangiography: a randomized trial. Surg Endosc. 2013;957-963. doi:10.1007/s00464-012-2540-9.

10. Sato N, Shibao K, Akiyama Y. Routine Intraoperative Cholangiography During Single-Incision Laparoscopic Cholecystectomy : a Review of 196 Consecutive Patients. J Gastrointest Surg. 2013;668-674. doi:10.1007/s11605012-2123-z

11. Experience F, Vauthey JN, Dindo D, Schulick RD, Santiban E De. The ClavienDindo Classification of Surgical Complications. 2009;250(2):187-196. doi:10. 1097/SLA.0b013e3181b13ca2

12. Yang $\mathrm{MH}$, Chen $\mathrm{TH}$, Wang $\mathrm{SE}$, et al. Biochemical predictors for absence of common bile duct stones in patients undergoing laparoscopic cholecystectomy. Surg Endosc. 2008;22(7):1620-4. doi:10.1007/s00464007-9665-2.

13. Barkun AN, Barkun JS, Fried GM, et al. Useful predictors of bile duct stones in patients undergoing laparoscopic cholecystectomy. McGill Gallstone Treatment Group. Ann Surg. 1994;220(1):32-9. doi:10.1097/00000658199407000-00006

14. Gurusamy KS, Giljaca V, Takwoingi Y, et al. Endoscopic retrograde cholangiopancreatography versus intraoperative cholangiography for diagnosis of common bile duct stones. Cochrane Database Syst Rev. 2015; 2(2):CD010339. doi:10.1002/14651858.CD010339.pub2.

15. Eikermann M, Siegel R, Broeders I, et al. Prevention and treatment of bile duct injuries during laparoscopic cholecystectomy: The clinical practice guidelines of the European Association for Endoscopic Surgery (EAES). Surg Endosc Other Interv Tech. 2012;26(11):3003-39. doi:10.1007/s00464-012-2511-1.

16. Buscarini E, Tansini P, Vallisa D, et al. EUS for suspected choledocholithiasis: Do benefits outweigh costs? A prospective, controlled study. Gastrointest Endosc. 2003;57(4):510-8. doi: 10.1067/mge.2003.149.

17. Tse F, Liu L, Barkun AN. ORIGINAL ARTICLE : Clinical Endoscopy EUS: a meta-analysis of test performance in suspected choledocholithiasis. Gastrointest Endosc. 2008;67(2):235-44. doi:10.1016/j.gie.2007.09.047.

18. Canto MIF, Chak A, Stellato T, et al. Endoscopic ultrasonography versus cholangiography for the diagnosis of choledocholithiasis. Gastrointest Endosc. 1998:47(6):439-48.

19. Aljebreen A, Azzam N, Eloubeidi MA. Prospective study of endoscopic ultrasound performance in suspected choledocholithiasis. J Gastroenterol Hepatol. 2008;23(5):741-5. doi:10.1111/j.1440-1746.2008.05318.x.

20. Nathanson LK, O'Rourke NA, Martin IJ, et al. Postoperative ERCP versus laparoscopic choledochotomy for clearance of selected bile duct calculi: a randomized trial. Ann Surg. 2005:242(2):188-92. doi:10.1097/01.sla. 0000171035.57236.d7. 
21. Poh BR, Ho SPS, Sritharan M, et al. Randomized clinical trial of intraoperative endoscopic retrograde cholangiopancreatography versus laparoscopic bile duct exploration in patients with choledocholithiasis. Br J Surg. 2016;103(9): 1117-24. doi:10.1002/bjs. 10207.

22. Bansal VK, Misra MC, Rajan K, et al. Single-stage laparoscopic common bile duct exploration and cholecystectomy versus two-stage endoscopic stone extraction followed by laparoscopic cholecystectomy for patients with concomitant gallbladder stones and common bile duct stones: A randomized con. Surg Endosc Other Interv Tech. 2014;28(3):875-85. doi:10. 1007/s00464-013-3237-4.

23. Tzovaras G, Baloyiannis I, Zachari E, et al. Laparoendoscopic Rendezvous Versus Preoperative ERCP and Laparoscopic Cholecystectomy for the Management of Cholecysto-Choledocholithiasis. Ann Surg. 2012;255(3):435-9. doi:10.1097/SLA. ob013e3182456ec0.

Submit your next manuscript to BioMed Central and we will help you at every step:

- We accept pre-submission inquiries

- Our selector tool helps you to find the most relevant journal

- We provide round the clock customer support

- Convenient online submission

- Thorough peer review

- Inclusion in PubMed and all major indexing services

- Maximum visibility for your research

Submit your manuscript at www.biomedcentral.com/submit 